\title{
Scheduling Program Analysis of Pressure Relief Device (PRD) According to RBI API 581 on Production Gas Separator System
}

\author{
Dwi Priyanta ${ }^{1}$, Nurhadi Siswantoro ${ }^{2}$, Muhammad Saifulloh ${ }^{3}$
}

\begin{abstract}
Pressure relief device (PRD) serves to control and limit the pressure by directing the flow into an additional path. In the process of purification of oil and gas, application of PRD is found in production gas separator system. However, based on API 581, the PRD also has a risk of failure that every oil and gas company need to conduct regular inspections to ensure the reliability of PRD. One approach to evaluate critically the PRDs for arranging and scheduling programs is to use the risk-based inspection (RBI) method. The RBI is a systematic approach to the method of inspection management of equipment or works unit based on the level of risk. Risk assessment for PRD is based on API RP 581 third edition. After knowing the level of risk for PRD, the risk needs to be evaluated. For acceptable risk, it can be used as a reference to determine the next inspection until risk target. Meanwhile, unacceptable risk should be inspected immediately after RBI analysis.
\end{abstract}

Keywords_failure, inspection management, purification, reliability, risk assessment, risk target.

\section{INTRODUCTION}

$\mathrm{S}$ afety is a main point to be fulfilled in petroleum

and gas company production. Safety becomes a main point because the characteristics of oil and gas itself that operated in high pressure and flammable environment. If there is any failure may affect to human, environment, and operation of production, one of the method that may reduce the failure because of high pressure is installed the safety device which is the application of Pressure Relief Device (PRD) [1]. PRD is a safety device that works for control and limit pressure by directing the flow of high pressure from the main system into system itself [2].

Pressure relief device may fail for release the over pressure can cause failure on a protected device. Based on America Petroleum Institute Recommended Practice 581, there are 2 models for failure in PRD [3]:

- Fail to Open (FAIL)

a. Stuck or fail to open (FTO)

b.Device partially open (DPO)

c. Opens above set pressure (OASP)

- Leakage Failure ( LEAK)

a.Leak past device (LPD)

b.Spurious/premature opening (SPO)

c. Device stuck open (DSO)

Due to the high risk of failure of PRD, the

\footnotetext{
${ }^{1}$ Dwi Priyanta, Department of Marine Engineering, Institut Teknologi Sepuluh Nopember, Surabaya 60111, Indonesia,Email: priyanta@its.ac.id

${ }^{2}$ Nurhadi Siswantoro, Department of Marine Engineering, Institut Teknologi Sepuluh Nopember, Surabaya 60111, Indonesia,Email: nurhadi@ne.its.ac.id

${ }^{3}$ Muhammad Saifulloh, Department of Marine Engineering, Institut Teknologi Sepuluh Nopember, Surabaya 60111, Indonesia,Email: Muhammad.saifulloh14@mhs.ne.its.ac.id
}

government regulation no. 111979 regulates the safety of work on the processing of oil and gas. After the probability and consequences of failure. In chapter IV, article 14 and 15 discusses about the use and inspection programs to undertaken to prevent possible problems that may occurred during petroleum processing. This regulation shall bind any company engaged in the oil and gas processing industry shall conduct inspections on any equipment owned including the PRD [4]. This is useful to ensure success and safety in the work area. Each company has its own program and scheduling inspection of the company's assets. However, there are times when the inspection program that they apply is not maximized so that they are looking for an appropriate and effective inspection method to reduce the cost of inspection and maintenance [5].

Furthermore, to evaluate and scheduling programs analysis for PRD, then the risk-based inspection (RBI) method is used in this research.

\section{METHOD}

Risk assessment is calculated by combining the probability of failure with the consequences of failure. The first step in this RBI study is to calculate the probability of fail to open and the probability of Leak [6].

The next step after the probability of failure is to calculate the consequences of failure. The consequences of failure are influenced by the size of the release hole, the discharge rate or the release mass, the detection and isolation system, etc.

After the probabilities and consequences of failure are obtained, then the risk can be calculated using RBI. The risk is then compared with the target risk, and the RBI assessment. RBI assessment is conducted to determine the inspection schedule and the 
appropriate inspection method for pressure vessel. Details of RBI work for PRD are shown in Figure 1.

\section{RESULT AND DISCUSSION}

\section{A. Probability of Fail (Fail)}

The fundamental calculation applied to the PRD for the case of failure to open is to estimate the overpressure demand case frequency (or demand level), PRD probability fails to open when needed, and the probability that the protected equipment under excess pressure will experience loss containment. So the equation (1) can be made [3].

$$
P_{f, j}^{p+d}=P_{f o d, j} \cdot D R_{j} \cdot P_{f, j}
$$

The $\mathrm{j}$ notation needs to be calculated for each of the possible excessive pressures that occur in relation to the PRD. Pf, j, is a function of time and the potential for excess pressure.

PRD Demand Rate is obtained by multiplying default initiating event frequencies and demand rate reduction factor as shown in equation (2). Default initiating event frequency and demand rate reduction factor are found in Table 7.2 API 581.

$$
D R_{j}=E F_{j} . . D R R F_{j}
$$

PRD Probability of Failure on Demand is the probability of PRD will fail to open when needed. API 581 provides default failure on the failure on demand rate developed from the industrial data. This default value is expressed as a Weibull curve modified by several factors to obtain the equation (3).

$$
P_{f, \text { prior }}^{\text {prd }}=1-\exp \left[-\left(\frac{\mathrm{t}}{\text { pupd }}\right)^{\beta}\right]
$$

Where :

$\mathrm{t}=$ time for inspection interval $\eta, \beta=$ weibull parameters

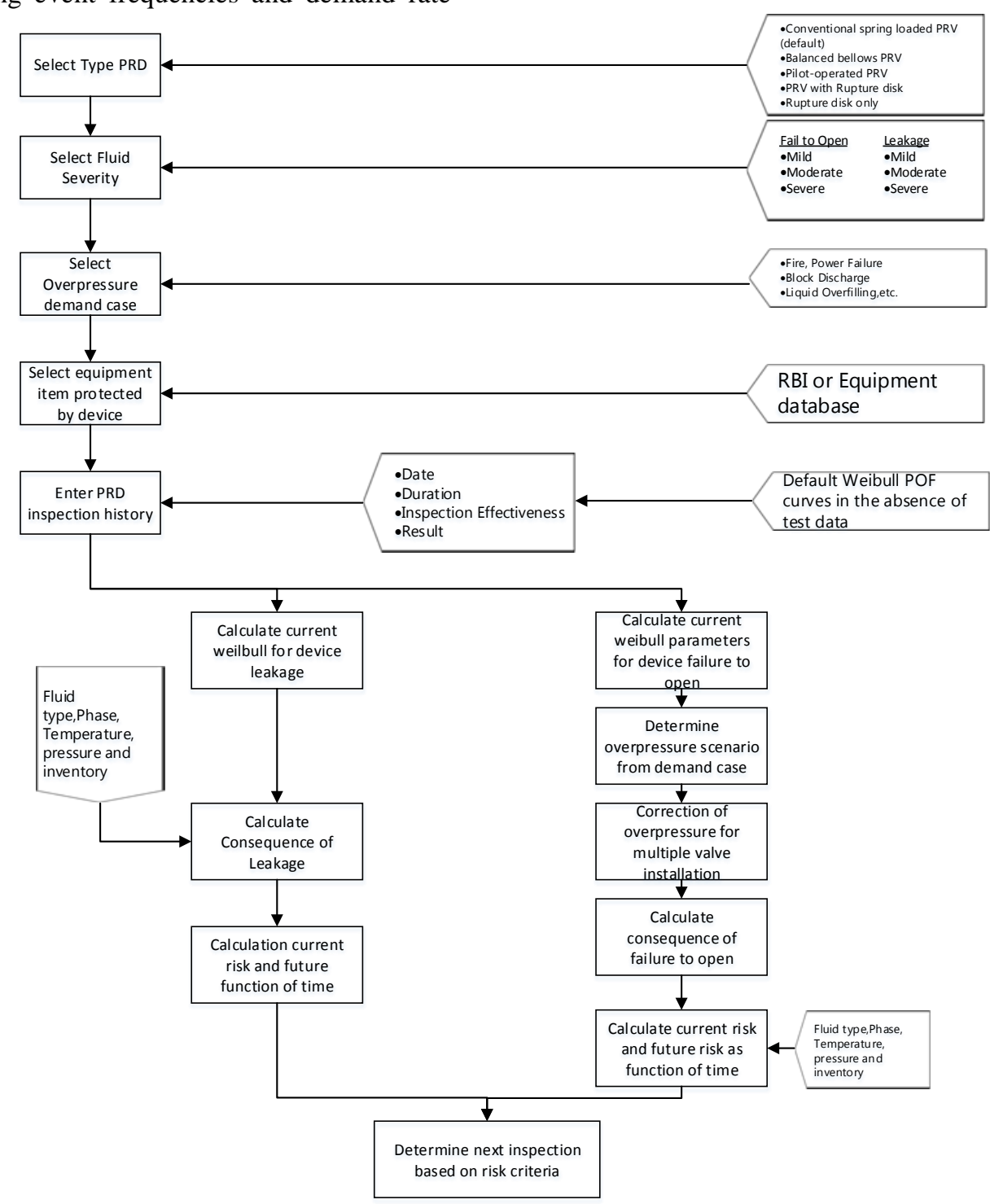

Figure 1. PRD RBI Methodology

(Source : API RP 581) 
The probability of protected equipment under excess pressure will have loss containment adjusted to the generic failure frequency of equipment multiplied by DF (damage factor). DF is determined based on the damage mechanism applicable to maintenance, inspection history, and equipment condition. Damage Factor on protected equipment is calculated as a function of time.

Damage adjusted to the failure frequency is calculated at the normal operating pressure of the equipment and adjusted when evaluating the PRD. When PRD fails, it fails to open when needed.
Pressure in protected equipment rises above operating pressure and in most cases significantly above MAWP (maximum allowable working pressure). Damage adjusted to the frequency of failure, which equals to the probability of loss of containment of the protected equipment under overpressure is calculated as the following equation (4):

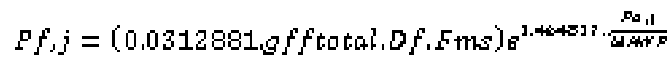

From the analyzed PRD obtained the probability of Fail to open results as in table 1 .

TABLE 1.

PRD PROBABILITY CALCULATION RESULTS ON PRODUCTION GAS SEPARATOR FAILED TO OPEN

\begin{tabular}{ccccc}
\hline PRD & $\begin{array}{c}P_{f \circ d, j} \\
\text { (failure/ demand) }\end{array}$ & $\begin{array}{c}D R_{j} \\
\text { (demand/ year) }\end{array}$ & $\begin{array}{c}P_{f, j} \\
\text { (failure/ year) }\end{array}$ & $\begin{array}{c}P_{f, j}^{\text {prd }} \\
\text { (failure/ year) }\end{array}$ \\
\hline PSV-0001A & 0.01025 & 0.0104 & $4.448 \mathrm{E}-06$ & $4.76 \mathrm{E}-10$ \\
PSV-1101A/B/C & 0.01465 & 0.0104 & $1.401 \mathrm{E}-04$ & $2.136 \mathrm{E}-08$ \\
PSV-1102A & 0.01465 & 0.0104 & $1.975 \mathrm{E}-04$ & $3.01 \mathrm{E}-08$ \\
PSV-1105A/B & 0.01465 & 0.0104 & $2.042 \mathrm{E}-04$ & $3.112 \mathrm{E}-08$ \\
\hline
\end{tabular}

B. Probability of Leak (POL)

The leakage case differs from the case of failure to open because POF is not a function of demand level that is not based on failure during continuous operation. Industrial Data Associated with leakage probability data in units per year (failure/year). There is no connection between any requests required. So the equation for calculating the probability of leak is shown in equation (5).

$$
P_{\mathrm{t}, j}^{p+d}=P_{\mathrm{l}}^{p+d} \cdot F_{s \mathrm{st}}
$$

The probability of leak in the PRD is a probability of PRD to fail because there is a leak in the previous equipment. API 581 provides default on leak rates developed from industrial data. This default value is expressed as a Weibull curve modified by several factors such as the type of PRD soft seats and environmental factors. So that equation (6) is obtained.

$$
P_{t, p+i o r}^{g+d}=1-\exp \left[-\left(\frac{\mathrm{t}}{\text { mugd }}\right)^{\beta}\right]
$$

The probability of a PRD leak needs to be adjusted according to the operating system adjacent to the set pressure as in (5). Set pressure factor, Fset is adjusted to PRD type provided API 581. The result of probability of Leak is shown in table 2 .

TABLE 2.

RESULTS OF PROBABILITY OF LEAK PRD CALCULATION ON PRODUCTION GAS SEPARATOR.

\begin{tabular}{cccc}
\hline PRD & $P_{\mathrm{I}}^{\text {p+d }}$ (failure/ year) & $F_{\text {set }}$ & $P_{[, j}^{\text {grd }}$ (failure/ year) \\
\hline PSV-0001A & 0.0182 & 0.7863 & 0.0143 \\
PSV-1101A/B/C & 0.0182 & 0.7863 & 0.0143 \\
PSV-1102A & 0.0182 & 0.7735 & 0.0141 \\
PSV-1105A/B & 0.0182 & 0.7692 & 0.0140 \\
\hline
\end{tabular}

\section{Consequence of Failure}

A consequent analysis is performed to determine the impact of a risk if it occurs on an equipment. The consequent analysis of the Central Processing Plant (CPP) uses a well-impacted area approach in the form of a large burning area, a large area of heat radiation that affects humans, and the area of toxic impact.
In the calculation of the consequence analysis of the failure of PRD based on API 581 begins by determining the value of overpressure when there is a failure in place of the operating pressure, Poj. Then the consequence of failure is calculated by using the following equation (7):

$C A=\max \left[C A_{\text {omd }}, C A_{\text {inj }}\right]$ 
International Journal of Marine Engineering Innovation and Research, Vol. 3(1), Des. 2018. 001-007

(pISSN: 2541-5972, eISSN: 2548-1479)

where:

$C A_{\text {emd }}=$ Consequence area component damage $\left(\mathrm{ft}^{2}\right.$

$C A_{\text {inj }}=$ consequence area personal injury $\left(\mathrm{ft}^{2}\right)$

The consequence value of component damage area is calculated by using equation (8) below:

$$
C A_{\text {emd }}=\max \left[C A_{\text {cmd }}^{\text {flam }}, C A_{c m d}^{\text {tox }}, C A_{\text {emd }}^{\text {nffnt }}\right] \text { (8) }
$$

Where :

$C A_{c+\pi d}^{f[a+n}=$ Consequence area flammable/explosion $\left(\mathrm{ft}^{2}\right)$

$C A_{c+\pi d}^{\operatorname{tax}}=$ Consequence area toxic $\left(\mathrm{ft}^{2}\right)$

$C A_{i+n d}^{\mathrm{n} \int \mathrm{fnt}}=$ Consequence area non-toxic nonflammable $\left(\mathrm{ft}^{2}\right)$

Then for consequence area personal injury with following equation (9):

$$
C A_{i+1 j}=\max \left[C A_{i+1 j}^{f[a+\pi}, C A_{i+1 j}^{t a x}, C A_{i+1 j}^{\mathrm{t} f \mathrm{ftr}}\right]
$$

Where :

$$
\begin{aligned}
C A_{i+j j}^{f[a+n}= & \text { Consequence area } \\
& \text { flammablelexplosion }\left(\mathrm{ft}^{2}\right) \\
C A_{i+1 j}^{\operatorname{tax}}= & \text { Consequence area toxic }\left(\mathrm{ft}^{2}\right) \\
C A_{i n j}^{n f n t}= & \text { Consequence area non-toxic non- } \\
& \text { flammable }\left(\mathrm{ft}^{2}\right)
\end{aligned}
$$

API 581 generally provides 2 categories of consequences, namely the consequences of component damage areas and injure personnel. The consequence of the area is strongly influenced by the mass of fluid and operating pressure contained in the RBI protected

\begin{tabular}{|c|c|c|c|c|}
\hline PRD & $C A_{\mathrm{c} m \mathrm{~d}}^{\mathrm{rl} \mathbf{m} \mathrm{m}}\left(\mathbf{m}^{2}\right)$ & $C A_{\mathrm{c} \log }^{\log }\left(\mathbf{m}^{2}\right)$ & $C A_{\mathrm{c} \rightarrow \alpha^{2}}^{0[02}\left(\mathbf{m}^{2}\right)$ & $C A_{\mathrm{c} \text { rod }}\left(\mathbf{m}^{2}\right)$ \\
\hline PSV-0001A & 16.895 & - & - & 16.895 \\
\hline $\mathrm{PSV}-1101 \mathrm{~A} / \mathrm{B} / \mathrm{C}$ & 17.277 & - & - & 17.277 \\
\hline PSV-1102A & 16.8228 & - & - & 18.8228 \\
\hline PSV-1105A/B & 16.8828 & - & - & 18.8228 \\
\hline
\end{tabular}
equipment.

Summary of calculation of area consequences for pressure relief device is shown in table 3 , table 4 and

\begin{tabular}{|c|c|c|c|c|}
\hline PRD & $C A_{\mathrm{in} i}^{\mathrm{l} \mathbf{m} m}\left(\mathbf{m}^{2}\right)$ & $C A_{i a j}^{200},\left(\mathbf{m}^{2}\right)$ & $C A_{i n i}^{0\lceil a t}\left(\mathbf{m}^{2}\right)$ & $C A_{\mathrm{in} i}\left(\mathbf{m}^{2}\right)$ \\
\hline PSV-0001A & 32.553 & 0.04834 & 0 & 32.553 \\
\hline PSV-1101A/B/C & 33.291 & 0.0483 & 0 & 33.291 \\
\hline PSV-1102A & 32.4146 & 0.04834 & 0 & 32.415 \\
\hline PSV-1105A/B & 32.4146 & 0.0487 & 0 & 32.415 \\
\hline
\end{tabular}
table 5 .

TABLE 3 .

CALCULATION RESULT THE CONSEQUENCE OF COMPONENT DAMAGE AREA

\begin{tabular}{|c|c|c|c|}
\hline PRD & $C A_{\mathrm{c} \text { ad }}\left(\mathbf{m}^{2}\right)$ & $C A_{\text {in } i}\left(\mathbf{m}^{2}\right)$ & $C A$ \\
\hline PSV-0001A & 16.895 & 32.553 & 32.553 \\
\hline $\mathrm{PSV}-1101 \mathrm{~A} / \mathrm{B} / \mathrm{C}$ & 17.277 & 33.291 & 33.291 \\
\hline PSV-1102A & 18.8228 & 32.415 & 32.415 \\
\hline PSV-1105A/B & 18.8228 & 32.415 & 32.415 \\
\hline
\end{tabular}

TABLE 4.

CALCULATION RESUlt THE CONSEQUENCE OF INJURY PERSONNEL AREA

TABLE 5.

FINAL CALCULATION RESULT OF CONSEQUENCE AREA OF PRD

D. Risk Assessment

A risk is calculated under RBI plan date conditions. API 581 provides the risk calculated using the following equation (10) [9][10].

$$
\text { Risk }=\text { PoF } x \text { CoF }
$$

The risk level at the pressure relief device is calculated by comparing the results of risk calculations on the RBI date and plan date with the risk target [3].

The risk ratio of each PRD analyzed is shown in the following table 6 .

Where:

PoF : Probability of Failure

$\mathrm{CoF}$ : Consequence of failure 
TABLE 6.

PRD RISK CALCULATION RESULT

\begin{tabular}{ccc}
\hline PRD & RBI date $\left(\mathbf{m}^{2} /\right.$ year $)$ & plan date $\left(\mathbf{m}^{2} /\right.$ year $)$ \\
\hline PSV-0001A & 0.46527 & 4.5988 \\
PSV-1101A/B/C & 0.4758 & 4.703 \\
PSV-1102A & 0.4557 & 4.5045 \\
PSV-1105A/B & 0.4532 & 4.4796 \\
\hline
\end{tabular}

Mapping Probability and Consequence values to a risk matrix is an effective method for presenting risks graphically. API 581 provides a relationship between the probability of failure and area-based consequence of failure as shown in table 7

TABLE 7.

NUMERICAL VALUES ASSOCIATED WITH POF AND AREA-BASED COF CATEGORIES

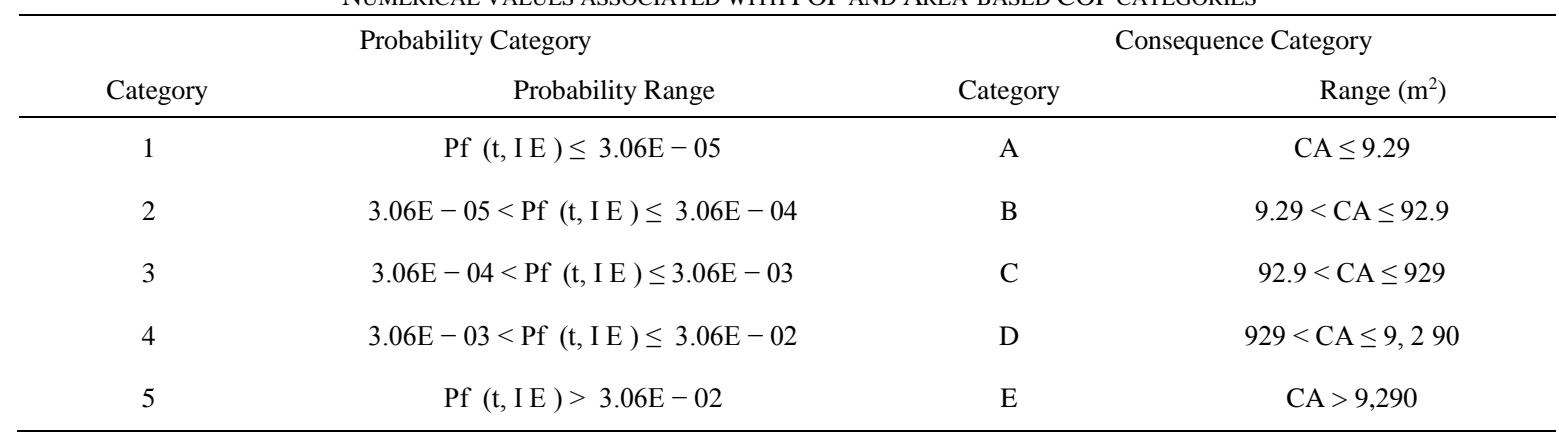

\section{E. Determining the risk level}

API 581 provides risk level categories into low risk, medium risk, medium high risk and high risk categories. Levels of risk gained with combines the probability of failure with consequences [6].

The probability of PRD failure analyzed ranged from 0.00140 failure/year - 0.00143 failure/year, so that based on Table 7 it can be seen that the PRD probability category is 4 .
While the consequences of the PRD analyzed ranged from $32.41 \mathrm{~m} 2-33.291 \mathrm{~m} 2$, so the consequence category of failure is B. Figure 8 shows the current level of risk experienced by the PRD. From the risk of PRD failure plotted in with the risk matrix, the risk level of PRD is the medium risk.

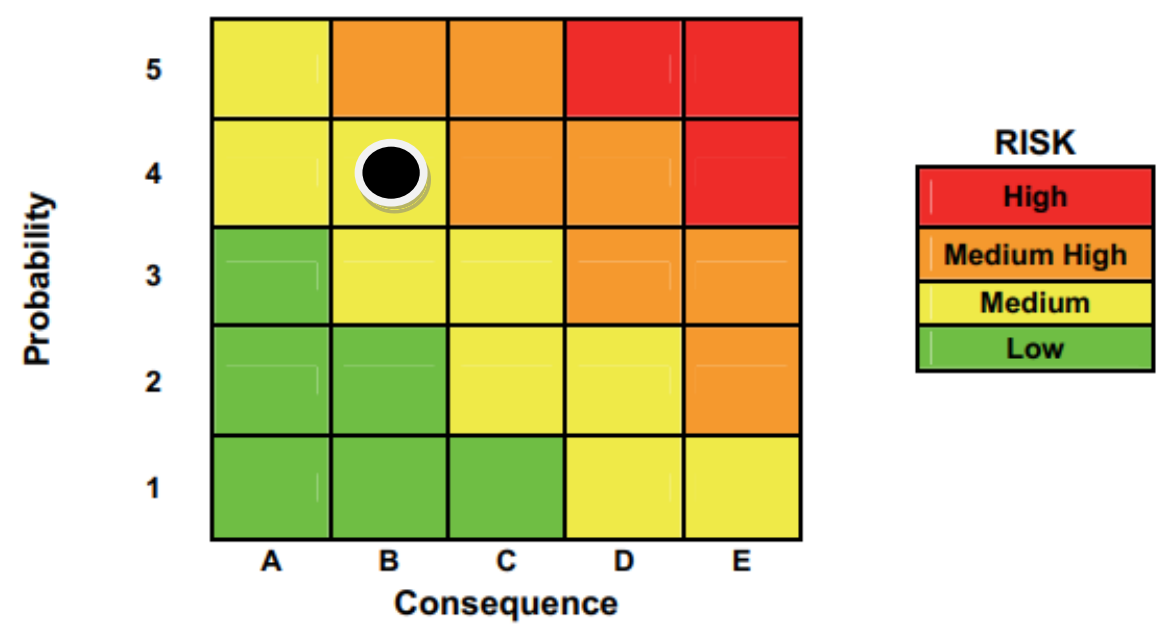

Figure. 8. Current risk Level (Source : API RP 581) 


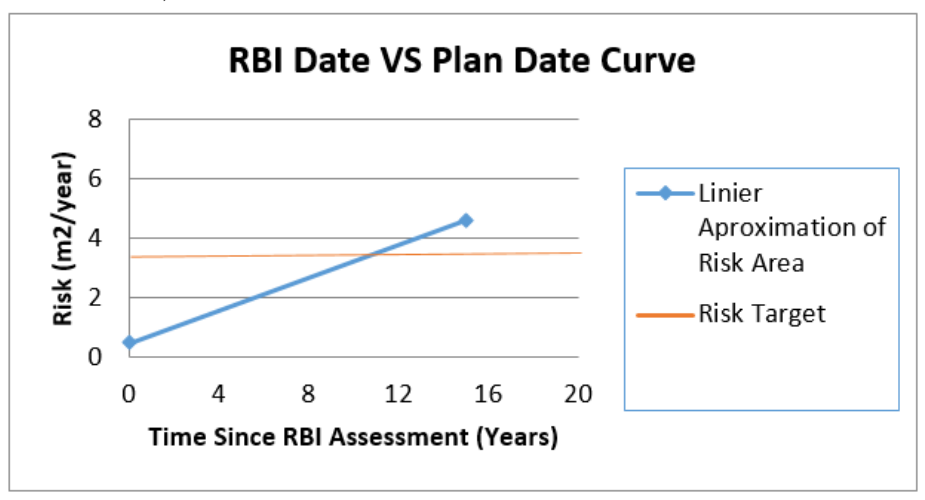

Figure. 9 . Comparison curve of approximation risk and risk target

F. Risk Based Inspection (RBI)

Assessment of RBI is done by comparing the total of risk at the time of RBI date and Plan date with the total of risk target to get target date. The target date is obtained by simulating the PRD life after RBI date to exceed the risk target so that the risk curve intersection on RBI date with the target risk curve is obtained. The curve in Figure 9 shows the comparison between the RBI date and the target date.

The target date can be calculated by interpolating the values in table 8 using the following equation (11):

TABLE 8.

INSPECTION DATE CALCULATION

\begin{tabular}{cccc}
\hline Data & Date & $\begin{array}{c}\text { Time since RBI } \\
\text { Assessment (years) }\end{array}$ & Risk Area $\left(\mathbf{m}^{2}\right)$ \\
\hline RBI Date & $8 / 25 / 2018$ & 0 & 0.46527 \\
Risk Target & $?$ & $?$ & 3.71 \\
Plan Date & $8 / 25 / 2033$ & 15 & 4.5988 \\
\hline
\end{tabular}

$$
\begin{aligned}
& \frac{y-y_{1}}{y_{2}-y_{1}}=\frac{x-x_{1}}{x_{2}-x_{1}} \\
& \frac{y-0}{15-0}=\frac{3.71-0.46527}{4.5988-0.46527} \\
& \mathrm{Y}=11.77
\end{aligned}
$$

So the target date is 11.77 years after the RBI date is done.

The total value after the inspection can be calculated by updating the value of modified characteristic life, pupd.

This study is expected to be examined by the effectiveness of a minimum inspection by Category $\mathrm{C}$ inspection 2 times prior to Inspection date

Inspection effectiveness category $2 \mathrm{C}=1 \mathrm{~B}$ (inspection by type $\mathrm{C}$ with scale 2 times proportional to inspection once using type B) and a risk of $3.07 \mathrm{~m} 2$ / year (acceptable).

\section{G. Inspection Plan}

Inspection effectiveness category $\mathrm{C}$ is visual test. Based on API 576 a full, visual on stream inspection should ensure the following [8]:

1. The Correct relief device is installed.

2. The company identification (such as a tag or stencil) provides means to establish the last test date and proper pressure setting for the equipment protected by the identified device.
3. That information matches the equipment file records and established test interval has not been exceeded.

4. No gags, blinds, closed valves, or piping obstructions would prevent the devices from functioning properly.

5. Seals installed to protect the spring setting and ring pin setting have not been broken.

6. The relief device does not leak. PRD has opened in service frequently leak. Detection and correction of this leakage eliminates product loss and possible pollution and prevents fouling and subsequent sticking of the valve. If the valve is a bellows valve, the bellows vent should be checked for leakage.

7. Bellows vents are open and clear, and the connected piping is routed to a safe location. A "safe location" could mean to atmosphere.

8. Upstream and downstream block valves are sealed or chained and locked in the proper position. Devices that ensure that a block valve is in its proper position include locking plastic bands, car seals, chains and padlocks, and special locking devices made especially for certain types of block valves. The field conditions should mirror the applicable piping and instrumentation diagrams (P\&IDs).

9. Vent stacks, discharge piping and small nipples are properly supported to avoid breakage or leakage. Inadequately supported or anchored nipples can be damaged during maintenance and by vibration. 
10. Valve body drains and vent stack drains are open.

11. Any lifting lever is operable and positioned properly.

12. Any heat tracing, insulation, or purge that is critical to the proper operation of the relief system is intact and operating properly.

13. A gauge installed as part of a combination of a rupture disk and a PRD or a device for checking pressure between a PRD and a block valve is serviceable. Verify that there is no pressure buildup between the rupture disk and pressure-relief valve.

14. Any rupture disk is properly oriented.

Although the interval selected for on-stream inspection should vary with circumstances and experience, a visual inspection that includes a check for leakage and vibration damage should follow each operation of a pressure-relief valve. Operating personnel assigned to the process unit may make these inspections provided that they are experienced to recognize any leakage or vibration damage.

\section{CONCLUSION}

According to the analysis research of PRD using RBI API 581 Method, then some conclusion could be taken as explain below:

1. The risk on PSV-0001A, PSV-1101A / B / C, PSV-1102A, PSV-1105A / B ranges from 0.4532 $\mathrm{m} 2$ / year $-0.4758 \mathrm{~m} 2$ / year. The risk for all PRDs analyzed when incorporated into the risk matrix has medium risk category and it is an acceptable level of risk.

2. Inspection planning for pressure relief device:

a. PSV-0001A is estimated in the 11th year after RBI analysis, on October 9, 2030

b. PSV-1101A / B / C is estimated in the 11th year after RBI analysis, on February 11, 2030

c. PSV-1102A is estimated in the 11th year after RBI analysis, which is September 11, 2030 d. PSV-110A / B is estimated in the 11th year after RBI analysis, which is October 9,2030

3. The inspection method that is expected to be applied is the visual inspection done without a pop test, where detailed documentation of PRD internal component condition is performed.

4. The calculation result using the RBI method shows the time of inspection for the PRD which is longer than the provisions of PERMEN ESDM No. 38 2017 , every 4 years. The different schedule of inspections can be caused by incomplete data.

\section{REFERENCES}

[1] M. Hendra, Analisis Penerapan Metode RBI dalam Pemeriksaan Keselamatan Kerja pada Industri MIGAS, Salambe: UI, 2010.

[2] M. Malek, Pressure Relief Device, USA: McGraw-hill Company,inc, 2006.

[3] API 581, Risk Based Inspection Technology, 3rd edition, Washington,D.C: API Publishing Service, 2016.

[4] D. Arina, Analisis Remaining Life dan Penjadwalan Program Inspeksi pada Pressure Vessel dengan Menggunakan Metode Risk Based Inspection (Remaining Life Analysis and Inspection Program Scheduling on Pressure Vessel using Risk Based Inspection Method), Surabaya: ITS, 2016.

[5] M. Hellemans, The Safety Valve Handbook, USA: ELSEVIER, 2009.

[6] API 580, Risk-Based Inspection Technology, 3rd edition, Washington,D.C: API Publishing Service, 2016.

[7] H. Devold, Oil and Gas Production Handbook An Introduction to Oil and Gas Production, Transport, Refining and Petrochemical Industry, USA: Etterstad, 2013.

[8] API 576, Inspection of Pressure Relief Device 3rd edition, Washington,D.C: API Publishing Service, 2009.

[9] D.GS Prayoga, Dwi Priyanta, Nurhadi Siswantoro, "Comparative Analysis of Probability of Failure Determination Using Weibull Distribution and Generic Failure Frequencies on Heat Exchanger Tube Bundles Based on API 581", International Journal of Marine Engineering Innovation and Research, vol. 2(3), pp. 210-215, 2018

[10] Dwi Priyanta, Nurhadi Siswantoro, Alfa Muhammad Megawan, "Risk Based Inspection of Gas-Cooling Heat Exchanger", International Journal of Marine Engineering Innovation and Research, vol. 1(4), pp. 317-329, 2017 